\title{
Determinants of Efficiency of Public Schools in Pakistan A Case Study of Multan District
}

\author{
Tahira Batool \\ Lecturer (Economics) Higher Education Department, Punjab \\ Dr. Muhammad Omer Chaudry \\ Associate Professor \\ School of Economics, Bahauddin Zakariya University, Multan
}

\begin{abstract}
The importance of effective allocation of resources and the quality of education sector has attracted a lot of attention in the developed countries in terms of academic performance. In contrast in developing countries like Pakistan there has been little work to estimate the performance of education sector to meet the increasing demand for improving the quality of education. The present study focuses on the assessment of technical and scale efficiency and efficiency differences among 134 public secondary schools of Multan district of Punjab province of Pakistan for the academic year 2013-2014 by two stages Data Envelopment Analysis. Number of students, percentage of teachers possessing master degree, average experience of teachers and number of classrooms has been used as inputs. While pass rate, percentage $\mathrm{A}^{+}, \mathrm{A}, \mathrm{B}$ and $\mathrm{C}$ grades have been taken as outputs. Average technical efficiency of schools is $85 \%$ and $91 \%$ under CRS and VRS assumption. Majority of schools are operating on decreasing returns to scale. In $2^{\text {nd }}$ stage DEA male schools showed positive significant impact on inefficiency of schools. Facility index, dummy for location and student teacher ratio was insignificant while teachers having professional degree showed unexpectedly highly significant positive impact on inefficiency scores of schools.
\end{abstract}

Keywords: Education, Data envelopment analysis, Technical efficiency, Scale efficiency, Schools

DOI: $10.7176 / \mathrm{JESD} / 10-9-03$

Publication date:May $31^{\text {st }} 2019$

\section{Introduction}

Education is the most important social instrument which enables human beings to enhance their capabilities by achieving their goals and objectives. It broadens the horizons of individuals; impart those opportunities by which individuals make their informed choices and play an important role in public decision making.

Issues relating to the performance and efficiency differences among schools and the determinants of quality of schools have led to controversies and ambiguities about educational policies in the past years (Hanushek, 1979, 2003). Several features i.e. absence of adequate information about the input and output prices, non-availability of clear consensus on what the real inputs and outputs are and what are the appropriate techniques to measure them, make it controversial (Hanushek, 1979).

Secondary education is considered terminal stage for students as it is gateway to higher education. The quality of professionals ultimately depends on the quality of secondary education. Issues such as impact of school size on the performance of schools and policies focusing at elevation of parental choice have been controversial now. In view of official budget, those schools will be efficient who utilize less expenditure while for parents those schools will be efficient whose students perform best in examination. In fact, different facilities (inputs) are accessible to different education institutions, so that they yield different achievements (outputs). Therefore the assessment of performance of schools becomes a difficult task in this type of multidimensional setting.

In Pakistan secondary education is started after primary education and it is followed by higher secondary education. Education of $9^{\text {th }}$ and $10^{\text {th }}$ class is included in secondary education while that of $11^{\text {th }}$ and $12^{\text {th }}$ is included in higher secondary education. There are 30,452 high schools in Pakistan; out of these public sectors contain 12,376 schools with $69 \%$ enrolment while private sector has 18,076 secondary schools with $31 \%$ enrolment of students (Pakistan Education Statistics 2013-2014). So to meet the increasing demand of quality of education in public schools with growing population, improvement in productive capacity and efficient utilization of resources in public schools is a matter of concern

Little is known about why public schools differ in their efficiencies and the factors causing adverse performance of public schools. So, in-depth analysis of the efficiency of public schools in Multan district of Punjab province of Pakistan has been taken to evaluate the performance of public schools for academic year 2013-2014. The study focuses on the assessment of technical and scale efficiency and efficiency differences secondary schools by applying non- parametric technique, two stages Data Envelopment Analysis. Technical efficiency has been measured by comparing school's production relative to the efficient production on the frontier under the assumption of Constant returns to scale (CRS) and Variable returns to scale (VRS) output oriented model. In the $2^{\text {nd }}$ stage of DEA to explain the efficiency differences among schools, inefficiency scores have been regressed on 
the exogenous or environmental factors. The analysis will provide school wise information for policy makers and school management, to make the effective plans to enhance the efficiency of public schools.

Next section provides review on previous research on topic. Section 3 presents methodology. Section 4 provides description of data. Estimated results have been discussed in section 5 which are followed by conclusion in last section.

\section{Literature Review}

(Farrell 1957) was the first to measure the technical efficiency in the literature. According to Farrell, a producer is technical efficient if maximum output can be produced within same set of inputs. It is not possible for the producer to increase one unit of output without increasing one unit of input or to decrease one unit of input without decreasing one unit of output. Charnes, Cooper and Rhodes (1978) generalized this concept and proposed a measure of data envelopment analysis (DEA) under the assumption of constant returns to scale by applying linear programming method for the efficiency measurement of non - profit organizations or service sectors e.g., schools which use multiple inputs and outputs but data on their market prices is not available.

In order to assess the performance of schools, DEA has been widely applied to evaluate empirical estimations. Pioneer studies employed this technique to evaluate efficiency of schools include Charnes et al. (1981) and Bessent and Bessent (1982). There is an ample literature in which this methodology was used such as (Mancebon and Molinero 2000; Tsakiridou and Stergiou, 2013; Ruggiero,1996; Mayston, 2003; Demir and Depren, 2010; Johnes et al.2001; Hirao, 2011; Tyagi et al. 2008; Burney et al.2013).

One of the drawbacks of DEA approach is that it does not take into account for non-discretionary factors and environmental differences while evaluating efficiency scores of DMUs. To correct this, Ray (1991) and Kirjavainen and Loikkanen (1998) estimated technical efficiency in the first stage of DEA by using multiple outputs with discretionary inputs e.g., which are under the control of the school and further extension was made by regressing efficiency scores on exogenous, socioeconomic or environmental variables in $2^{\text {nd }}$ stage DEA by applying OLS or tobit regression

Previous literature has also shown that student characteristics such as socio economic status and background (Alexander and Jaforullah, 2004) gender and congenital ability (Feinstein and Symons, 1997) and size of family tend to have significant impact on performance of students rather than school inputs. Female students showed better performance in different courses than their male counterpart (Waldo, 2007).

Majority of studies have derived the efficiency of education in developed countries using approach of nonparametric production function while there is a far little body of literature in developing countries which has assessed school efficiency such as Chile, India, Iran and Thailand (Mizala et al., 2002; Tyagi et al., 2008; Kazemi, 2011 and Kantabutra, 2009)

\section{Methodology}

Data envelopment analysis (DEA) is non-parametric method to estimate the relative efficiency of set of similar units, usually refer as decision making units (DMUs) which use multiple inputs to produce multiple outputs for which price data is not available. DEA applies mathematical programming approach to measure the efficiency by formulating the "best practice" production frontier which is the linear combination of inputs and outputs of observed data. This frontier is consisted of those producers that utilize their resources efficiently i.e. they produce maximum output within given level of inputs or given set of outputs with minimum quantity of inputs. This efficient frontier can be used as "benchmark" relative to which the efficiency of all other DMUs (which show the deviation from the efficient frontier) is measured. This benchmark gives a DMU $100 \%$ efficiency, by gaining score 1. Inefficient DMUs relative to this benchmark will have efficiency score less than 1. For example a DMU has an efficiency score of 0.85 then it means this DMU is utilizing $85 \%$ resources efficiently or it is $15 \%$ less efficient relative to the unit producing on efficient frontier. So, it can be concluded that this inefficient DMU has $15 \%$ output increasing potential or it has to increase the outputs by $15 \%$ in order to be on efficient frontier. The closer actual output to this benchmark quantity, the greater will be the efficiency. Deviation from this frontier does not assume noise or random term. It is the failure of economic or producing unit to deviate from efficiency frontier so it is termed as deterministic production frontier. Schools have little control over inputs but they can enhance their performance by influencing the outputs. Therefore, output oriented technique will be used in the analysis.

In DEA it is option to analyse efficiency under the assumption of constant returns to scale (CRS) and variable returns to scale (VRS). When DMUs perform optimally and when production is not influenced by scale of operation the assumption of CRS is appropriate. Large schools are efficient similar to small ones in transforming inputs to outputs but in practice there are some constraints like imperfect competition or government regulations etc, that make DMUs not to operate at an optimal scale. So, Banker et al. (1984) proposed VRS model known as BCC model, as an extension of CCR model in DEA. BBC model permits to divide the inefficiencies into scale and technical inefficiency measure.

CRS assumption of DEA and VRS assumption DEA are applied on the same observations for measuring 
scale efficiency. If both assumptions of DEA give different technical efficiency scores for a DMU then it will indicate the presence of scale inefficiency. Scale efficiency is derived by the ratio of technical efficiency score under CRS and technical efficiency score under VRS

\subsection{Second stage DEA (inefficiency analysis)}

To explain the efficiency difference among schools we will regress inefficiency scores on the exogenous factors. Exogenous variables are the factors which may or may not be under the control of schools but affect the efficiency of schools. These are the factors which cause inefficiency. Hence, the estimated equation of inefficiency model can take the following form

In the above equation $\alpha_{\mathrm{i}}$ is the inefficiency score of the school $i$ which is one minus the efficiency score under CRS which were derived from the first stage DEA so $\alpha_{\mathrm{i}}=1-\mathrm{EFF}_{\mathrm{i}}$

We have employed truncated regression technique in $2^{\text {nd }}$ stage DEA. There are many techniques e.g. tobit regression technique, OLS etc. which have been used in $2^{\text {nd }}$ stage DEA. Though many studies have employed tobit regression analysis in $2^{\text {nd }}$ stage DEA, but it has been criticized due to its biased estimators. Therefore, we have applied truncated regression technique which was proposed by Simar and Wilson (2007).

\section{Data and Variables}

For the analysis of efficiency of secondary schools of Multan district in the Punjab province of Pakistan, we have used cross sectional data for the academic year 2013-2014. The data has been derived from the two sources, the first source was the website of School education department Government of Punjab and the second source was the Board of Intermediate and Secondary Education BISE Multan.

Multan city is located in Punjab province of Pakistan. Multan district covers an area of 3,721 square kilometres and includes tehsil Multan, tehsil Shujabad and tehsil Jalalpur Pirwala. The purpose of this study is to evaluate the performance of 134 secondary education of Multan district. In the analysis, technical efficiency of 100 schools of tehsil Multan, 20 schools of tehsil Shujabad and 14 schools of tehsil Jalalpur Pirwala of Multan District will be estimated. The data included 93 secondary schools for boys and 41 secondary schools for girls. 119 urban and 15 rural schools have also been analysed.

The choice of inputs is less problematic as compared to outputs (Smith and Street, 2006). Traditional inputs in education production are the expenditures on teachers and students, but data on these variables is not available in settings of this study. So, following the studies of Chakraborty et al. (2001); Meunier (2008); Currier (2007), variables related to school and teacher characteristics have been used as inputs. 4 inputs have been taken in this study.

1. No of Class rooms

2. School size (measured as number of students)

3. Percentage of teachers possessing master degree

4. Teaching experience of teachers ( measured in average)

Total number of classrooms in a school is used as a proxy of capital and it indicates the availability of physical resources. In our study we have considered total number of students enrolled in each school for school size following the study of Pereira and Moreira (2007).Variable of academic qualification and average experience of teachers has been taken by following the study of Kirjavainen and Loikkanen (1998) and Chakraborty et al. (2001). According to their studies, these variables in statistical analysis seem to have little impact on educational outcomes of students but efficiency distribution and ranking can be affected by them. So, academic qualification of teachers has been measured by taking percentage of teachers in each school possessing master degree (sixteen years of education).

In Pakistan secondary school education lasts for two years. After completing $9^{\text {th }}$ grade, standardized tests of academic subjects are taken from students and at the end of $10^{\text {th }}$ grade students again give tests of the $2^{\text {nd }}$ part of the same subjects. Successful students are awarded Secondary School Certificate (SSC) upon the completion of these grades. $9^{\text {th }}$ and $10^{\text {th }}$ grade final examination is referred as 'matriculation' in Pakistan. Passing of matriculation examination grants the students general ability and certain academic requirements to enter in university. Grades achieve by students in final examination are the good indicators to evaluate the quality of education. So, we have taken matriculation results of academic year 2014 as our key outputs.

1. Pass rate

2. Percentage of students achieved $\mathrm{A}+$ grade

3. Percentage of students achieved $\mathrm{A}+$ grade

4. Percentage of students achieved B grade

5. Percentage of students achieved $\mathrm{C}$ grade

The variable of pass rate has used in the study by taking the percentage of pass students from the students appeared in the final examination of matriculation. All the students of different schools sit for the similar examination, so pass rate becomes a good indicator to evaluate the performance of schools. Percentage of students 
achieved A plus grade in final examination of matriculation has been taken by measuring percentage of students achieved eighty percent result or A plus grade from the total number of passing students. Percentage of students achieved A grade or seventy percent result and percentage of students achieved B and C grade in final matriculation examination has been taken as outputs.

There are some non- discretionary inputs which are not under the control of school but their impact on the performance of schools is very significant. These are the factors which cause inefficiency. Following 5 variables have been considered for the study to evaluate the determinants of inefficiency

1. Dummy for location

2. Dummy for gender

3. Percentage of professional qualified teachers

4. School Facility Index

5. Student teacher ratio

To analyse the impact of location i.e. rural and urban schools on the inefficiency of schools dummy for location has taken in the study. Similarly, dummy for gender has used in the study to check the impact of female and male schools on the inefficiency scores. Tsakiridou and Stergiou (2013) and Nghiem et al. (2014) used these dummy variables in their studies. Number of teachers in each school possessing degree of B.ed; have been considered for the study. School facility index included facilities of computer lab, library, facility of playground and sports for the students. Number of students per teacher indicates the degree of intensity of utilization of teachers. Hence, the estimated equation of inefficiency model can take the following form

$\alpha_{\mathrm{i}}=\beta_{0}+\beta_{1} \mathrm{UR}_{\mathrm{i}}+\beta_{2} \mathrm{MF}_{\mathrm{i}}+\beta_{3} \mathrm{FI}_{\mathrm{i}}+\beta_{4} \mathrm{DEG}_{\mathrm{i}}+\beta_{5} \mathrm{STR}_{\mathrm{i}}$

Descriptive statistics of inputs, outputs and exogenous variables, used in the study has been given in the table 1

Table1: Descriptive Statistics of Variables

\begin{tabular}{lccccc}
\hline Variables & No. of observations & Mean & Minimum & Maximum & Standard deviation \\
\hline Outputs & & & & & \\
Pass rate & 134 & 81.181 & 45 & 100 & 12.053 \\
Percentage A ${ }^{+}$grade & 134 & 5.145 & 0 & 25 & 5.330 \\
Percentage A grade & 134 & 12.623 & 0 & 35.710 & 8.212 \\
Percentage B grade & 134 & 26.364 & 0 & 100 & 12.903 \\
Percentage C grade & 134 & 39.510 & 0 & 95.690 & 14.092 \\
Inputs & & & & & \\
Students & 134 & 737.209 & 153 & 2954 & 483.616 \\
Class rooms & 134 & 14.963 & 4 & 55 & 8.178 \\
Academic qualification & 134 & 44.381 & 18.180 & 70.590 & 11.363 \\
Experience & 134 & 18.659 & 10.478 & 25.615 & 3.214 \\
Inefficiency model & & & & & 0.316 \\
Dummy for location & 134 & 0.888 & 0 & 1 & 0.463 \\
Dummy for gender & 134 & 0.694 & 0 & 1 & 8.505 \\
Student teacher ratio & 134 & 29.450 & 10.890 & 63 & 0.226 \\
School facility index & 134 & 0.713 & 0.250 & 1 & 11.062 \\
Professional degree & 134 & 15.104 & 4 & 55 &
\end{tabular}

Note: Results have been obtained using software E-views

\section{Empirical results}

Software DEAP version 2.1 which is student free version has been used to estimate efficiency of public secondary schools. Efficiency of 134 schools assuming CRS, VRS and SE has been estimated. Second stage DEA has been conducted to evaluate the impact of exogenous factors on the inefficiency scores.

\subsection{Efficiency Analysis}

Technical efficiency of schools has been estimated in the model by using multiple inputs and outputs. Descriptive statistics of overall efficiency scores of public secondary schools under the assumption of CRS, VRS and scale efficiency has been given in table 2 
Table 2: Descriptive statistics of overall efficiency scores

\begin{tabular}{llll}
\hline & CRS & VRS & SE \\
\hline Mean efficiency & 0.845 & 0.908 & 0.926 \\
Minimum efficiency & 0.460 & 0.546 & 0.606 \\
Maximum efficiency & 1 & 1 & 1 \\
Standard deviation & 0.144 & 0.097 & 0.088 \\
No. Of Observations & 134 & 134 & 134 \\
No. Of efficient schools & 37 & 42 & 37 \\
\hline
\end{tabular}

Source: Author's own calculations

Schools which can produce maximum outputs within given inputs are technical efficient. In the analysis 37 schools out of 134 schools are technical efficient under CCR (CRS) model. Only 28\% schools are performing efficiently. Remaining 72\% schools are technical inefficient as their efficiency score is below 1 . Average efficiency of public schools of Multan district is $85 \%$. This means that these schools have the potential to increase their output by $15 \%$ on average with the same inputs. There are wide variations in the efficiency scores of public secondary schools in Multan district. Mean efficiency of schools is 91\% under BCC (VRS) model. On average schools can increase their output by $9 \% .42$ schools out of 134 schools are efficient under the assumption of VRS. It shows that 92 schools are inefficient or which are producing below the efficient frontier with minimum efficiency of $55 \%$. It concludes that efficiency scores of CRS are lower than VRS which reflect that scale inefficiencies exist. Under VRS assumption, efficiency scores are generally higher than assumption of CRS. So, in the present analysis the schools which were less efficient under the assumption of CRS improved efficiency in VRS assumption. Analysis of scale efficiency showed 37 schools to be scale efficient with minimum scale efficiency of 0.61 . 97 schools could improve their scale efficiency within given inputs.

Efficiency analysis of male and female schools separately showed interesting results. On average female schools are found to be efficient, while male schools are not performing better than female schools. This result is consistent with the study of Waldo (2007) in which female students were found to be efficient than male students.

Descriptive statistics of table 3 shows that female schools are $29 \%$ efficient while male schools are $27 \%$ efficient under the assumption of CRS. Male schools are on average $83 \%$ efficient so they can increase their efficiency by $17 \%$ by utilizing same inputs while female schools are on average $88 \%$ efficient and they have the potential to increase their output by $12 \%$. . 25 schools of male out of 93 schools are performing on efficient frontier while 12 out of 41 schools of female are technically efficient.

Table 3: Descriptive statistics of efficiency scores of male and female schools

\begin{tabular}{llll}
\hline & CRS & VRS & SE \\
\hline Male & & & \\
Mean efficiency & 0.830 & 0.900 & 0.918 \\
Minimum efficiency & 0.460 & 0.546 & 0.634 \\
Maximum efficiency & 1 & 1 & 1 \\
Standard deviation & 0.154 & 0.106 & 0.092 \\
No. Of observations & 93 & 93 & 93 \\
No. Of efficient schools & 25 & 30 & 25 \\
& & & \\
Female & & & \\
Mean efficiency & 0.879 & 0.926 & 0.946 \\
Minimum efficiency & 0.545 & 0.722 & 0.606 \\
Maximum efficiency & 1 & 1 & 1 \\
Standard deviation & 0.115 & 0.070 & 0.076 \\
No. Of observations & 41 & 41 & 41 \\
No. Of efficient schools & 12 & 12 & 12 \\
\hline
\end{tabular}

Source: Author's own calculations

On average male schools have $90 \%$ efficiency under VRS assumption of DEA. They should increase $10 \%$ output to become efficient. Scores of efficiency under the assumption of CRS and VRS are not similar which shows that scale inefficiencies exist. Minimum VRS efficiency score is $55 \%$ while 30 schools or $32 \%$ male schools are performing on efficient frontier under VRS. $68 \%$ male schools have the potential to maximise their output or improve their results. Under VRS efficiency of male schools improved relative to female schools.

Analysis has also been conducted for the efficiency difference of urban and rural schools. Descriptive statistics of rural and urban schools have been shown in table 4. On average urban schools have mean efficiency of $84 \%$ while rural schools have $90 \%$ efficiency under CRS assumption of DEA. Rural schools should increase on average $10 \%$ output while urban schools can increase $16 \%$ output within given quantity of inputs. 
Table 4: Descriptive statistics of efficiency scores of urban and rural schools

\begin{tabular}{llll}
\hline & CRS & VRS & SE \\
\hline Urban & & & \\
Mean efficiency & 0.838 & 0.904 & 0.923 \\
Minimum efficiency & 0.460 & 0.546 & 0.606 \\
Maximum efficiency & 1 & 1 & 1 \\
Standard deviation & 0.147 & 0.101 & 0.089 \\
No. Of observations & 119 & 119 & 119 \\
No. Of efficient schools & 32 & 37 & 32 \\
& & & \\
Rural & & & \\
Mean efficiency & 0.897 & 0.940 & 0.952 \\
Minimum efficiency & 0.674 & 0.852 & 0.764 \\
Maximum efficiency & 1 & 1 & 1 \\
Standard deviation & 0.110 & 0.053 & 0.083 \\
No. Of observations & 15 & 15 & 15 \\
No. Of efficient schools & 5 & 5 & 5 \\
\hline
\end{tabular}

Source: Author's own calculations

2 urban schools out of 119 or $27 \%$ urban schools are producing maximum output within given inputs while 5 schools out of 15 or $33 \%$ rural schools are technical efficient under CRS. Under VRS both rural and urban schools improved their efficiency scores. It concludes that urban and rural schools CRS efficiency scores are confounded by scale inefficiencies. $31 \%$ urban schools are found to be efficient under VRS assumption of DEA while rural schools are 33\% efficient. So, 69\% urban schools and 29\% rural schools are inefficient under VRS assumption. Schools which are efficient in CRS are also found to be efficient under VRS while overall schools improved their efficiency under VRS.

\subsection{Regression Analysis (2nd stage DEA)}

Results for regression analysis have been obtained by using software Stata 11 which is student free version. The main purpose behind this second stage analysis is to evaluate the determinants of inefficiency. How inefficiency scores of schools can be explained by exogenous or environmental factors which include location, gender, facility index, teachers possessing professional degree and student teacher ratio. All these exogenous variables are treated as independent variables while inefficiency scores under CRS of simple model are kept as dependent variables in $2^{\text {nd }}$ stage DEA truncated regression analysis. Estimated results have been shown in the table 5

Table 5: Second Stage Truncated Regression Estimates

\begin{tabular}{llll}
\hline Variables & Coefficient & Standard Error & Z-value \\
\hline Dummy for location & 0.056 & 0.051 & 1.11 \\
Dummy for gender & 0.135 & 0.040 & $3.14^{*}$ \\
School facility index & -0.040 & 0.071 & -0.56 \\
Professional degree & 0.007 & 0.001 & $5.43^{*}$ \\
Student teacher ratio & 0.001 & 0.002 & 0.71 \\
Constant & -0.072 & 0.100 & -0.72 \\
Sigma & 0.118 & 0.012 & $10.25^{*}$ \\
\hline
\end{tabular}

* significant at $95 \%$ level of significance

$\mathrm{Z}$ value can be treated as $\mathrm{t}$ value in truncated regression analysis. Results show that the impact of location e.g. rural schools or urban schools is not significant. There is no impact of location of schools on the inefficiency of schools i.e. performance of students' is not influenced by whether schools locate in urban areas or rural areas

Dummy for gender has significant impact on inefficiency of schools. This is the most interesting result as the positive coefficient sign indicated that inefficiency increases when male schools increases. It concludes that male students perform poor as compare to female students in examinations as it has proved in the results of $1^{\text {st }}$ stage DEA that female schools perform better in exams rather than males or in other words female schools are more efficient than male schools. As female schools increases inefficiency reduces or efficiency increases. This result is consistent with the study of Alexander and Jaforullah (2004) efficiency analysis in New Zealand secondary schools. It might due to common belief that female students are more hard worker and ambitious than male students.

Coefficient of school facility index is negative and shows that when facilities for library, computer lab, playground and sport facilities increases inefficiency reduces but this variable is insignificant in the present study. The insignificant impact of facility index on inefficiency scores is due to the reason that in the secondary schools, library and computer lab does not play an important role on students' performance in examinations. In Pakistan at secondary school level, the course is designed by the central curriculum committee and standardized text books 
are used. Therefore, the tendency of using library and at secondary school level is low. Similar is the case for computer lab, so, library and lab facilities are insignificant in explaining efficiency differences among schools. Support facilities also have no significant impact on students' performance as these activities are extracurricular activities ,which involve only in the mental and physical exercise of students, but insignificant in explaining schools' performance or their efficiency in terms of students' achievements.

The most unexpected or unusual result is highly significant positive impact of teachers' professional qualification on inefficiency scores. Hanushek (1986) concluded in his study that teachers' qualification or quality has no impact on students' achievement. In Pakistan government hire in public schools only professional qualified teachers and in the present study teachers having professional degree seem to have negative impact on students' performance. It might be the reason that teachers have only degree, not training to teach students. There is quantity of professional qualified teachers' but no teaching quality. As data is cross sectional and not very large so due to small variation it could not show insignificant or positive impact on students' performance.

Student teacher ratio is insignificant in explaining inefficiency of schools. Kirjavainen et al. (2006) also found insignificant impact of student teacher ratio on students' performance. Hence, though the result is insignificant, but it supports the common belief that higher number of students per teacher decrease efficiency. Coefficient of this variable has positive sign which shows that as student per teachers increase inefficiency increase. Theoretically it is explained that if class size is large and there are more students, then each student will get less attention of teacher. This will result in low or poor performance of students.

It is important to note that sigma value is 10.25 which depicts that the overall model is significant in explaining the observed efficiency variations in public secondary schools of Multan district.

\section{Conclusion}

DEA technique assuming $\mathrm{BCC}$ and $\mathrm{CCR}$ output oriented model has been used in the analysis of technical efficiency of public secondary schools of Multan district. Results conclude that inefficiencies exist in the production of secondary schools. Average technical efficiency of schools is $85 \%$ under CRS assumption of DEA methodology. Efficiency ranges from $46 \%$ to $100 \%$. Results of VRS assumption showed that average efficiency is $91 \%$. Schools improved their efficiency when VRS assumed which shows that scale inefficiencies exist along with technical inefficiencies. Majority of schools are operating on decreasing returns to scale, which implies that school size is so large, that they are not producing efficiently. DEA methodology implies that there are variations in efficiency scores among public secondary schools.

Regression analysis in $2^{\text {nd }}$ stage DEA showed that dummy for gender is significant in explaining efficiency differences among schools. Male schools showed positive significant impact on inefficiency of schools. Facility index, dummy for location and student teacher ratio was insignificant while teachers having professional degree showed unexpectedly highly significant positive impact on inefficiency scores of schools.

DEA is a technique or tool to diagnose the inefficiencies among schools but it does not provide any strategy for inefficient schools to become efficient. Strategies should be implemented by diagnosing the operations of efficient schools, which would be helpful for inefficient schools to become efficient. Results of technical efficiency of schools under CRS and VRS provide starting initiative for further investigation to evaluate and improve the performance of secondary education. If inefficiency is minimized then wastage of resources can be reduced and resaved to expand the good quality of education of public schools in Multan.

\section{References}

Alexander, W. R. J., \& Jaforullah, M. (2004). Explaining efficiency differences of New Zealand secondary schools (Economics Discussion Papers Series No. 403). University of Otago. Retrieved from http://hdl.handle.net/10523/899

Bessent, A., Bessent, W., Kennington, J., and Reagan, B. (1982). An Application of Mathematical Programming to Assess Productivity in the Houston Independent School District. Management Science, 28( 12), 1355-1367

Bradley, S., Johnes,G., and Millington, J. (2001). The effect of Competition on the efficiency of secondary schools in England. European Journal Of Operational Research 135, 545-568.

Burney, N.A., Johnes , J., Enezi, M.A., and Musallam, A.L. (2013). The efficiency of public schools: the case of Kuwait. Education Economics, 21(4), 360-379.

Banker, R.D., Charnes, A., and Cooper, W.W. (1984). Some Models for Estimating Technical and Scale

Inefficiencies in Data Envelopment Analysis. Management Science, 30, 1078-1092.

Currier, S.R. (2007). Assessing the Efficiency of Oklahoma Public Schools: A Data Envelopment Analysis. South western Economic Review, 131-144.

Chakraborty, K., Biswas, B., and Lewis, W.C. (2001). Measurement of Technical Efficiency in Public Education: A Stochastic and Nonstochastic Production Function Approach. Southern Economic Journal, 67( 4) , 889905.

Charnes, A., Cooper, W., and Rhodes, E. (1981). Evaluating Programme and Marginal Efficiency: An 
Application of Data Envelopment Analysis to Programme Follow Through. Management Science, 27(6)

Charnes, A., Cooper, W.W., and Rhodes, E. (1978). Measuring the Efficiency of Decision Making Units. European Journal of Operational Research, 2, 429-444.

Coelli, T.J., (1996). A Guide to DEAP Version 2.1: A Data Envelop Analysis (Computer) Program. UNE (CEPA) Working Papers 8, 1-50.

Demir, I., and Depren,O. (2010). Assessing Turkey's secondary schools performance by different region in 2006 . Procedia Social and Behavioral Sciences, 2 , 2305-2309.

Feinstein, L., and Symons, J., (1997). Attainment in secondary school. Discussion Paper, Centre for economic performance, London school of economics.

Farrell, J. J. (1957). The Measurement of Productive Efficiency. Journal of the Royal Statistical Society Series A, $120,253-281$

Hanushek, E. (1986). The economics of schooling, production and efficiency in public Schools. Journal of Economic Literature, 24(3).

Hanushek, E.A. (1979). Conceptual and Empirical issues in the Estimation of Educational Production Functions. The Journal of Human Resources, 14(3), 351-388.

Hanushek, E.A. (2003). The Failure of Input- Based Schooling Policies. The Economic Journal, 113, 64-98

Hirao, Y. (2011). Efficiency of the top 50 business schools in the United States. Applied Economics 19(1), 73-78.

Kazemi, I., Gharakhani, M., and Haji, H.A. (2011). A Robust DEA model for measuring the relative efficiency of Iranian high schools. Management science letters, 389-404

Kantabutra, S. (2009). Using a DEA management tool through a non parametric approach: an examination of urban-rural effects on Thai school efficiency. International Journal of Education Policy \& Leadership, 4(20).

Kirjavainen,T., and Loikkanen,H.A. (1998). Efficiency Differences of Finnish Senior Secondary Schools: An Application of DEA and Tobit Analysis . Economics of Education Review, 17( 4), 377-394.

Mancebon, M.J., and Molinero,C.M. (2000). Performance in Primary Schools. The Journal of the Operational Research Society, (51), 843-854

Mizala, A., Romaguera, P., and Farren, D. (2002). The Technical Efficiency of Schools in Chile . Applied Economics ,34 (12), 1533-1552

Meunier, M. (2008). Are Swiss Secondary schools Efficient. In P.J. N. C. Soguel, Governance and performance of Educational Systems, Geneva : springer. , 187-202

Pereira, M.C., and Moreira, S.(2007). Efficiency Of Secondary Schools In Portugal: A Stochastic Frontier Analysis. Estudos e Documentos de Trabalho Working Paper 6, Banco de Portugal

Pakistan Education Statistics (2013-2014). Ministry of Federal Education and Professional Training, Government of Pakistan.

Ray, S. C. (1991). Resource-Use Efficiency in Public Schools: A Study of Connecticut Data. Management Science, $37(12), 1620-1628$

Ruggiero, J. (1996). Efficiency of Educational Production: An Analysis of New York School Districts. The Review of Economics and Statistics, 78( 3), 499-509.

Simar, L., and Wilson, P. (2007). Estimation and inference in two-stage, semi-parametric models of production processes. Journal of Econometrics, 136, 31-64

School Education Department Punjab .www.schools.punjab.gov.pk/accessed multiple times

Smith, P.C., and Street, A. (2006). Analaysis of secondary school efficiency. Nottingham: DFES publications

Tsakiridou, H., and Stergiou, K. (2013). Evaluating the efficiency of Primary School Education. Advanced Research in Advanced Areas, 279-286

Tyagi, P., S.P. Yadav., and S.P. Singh. (2008). Evaluation of elementary school performance: An application of data envelopment analysis. Roorkee, India: Department of Mathematics, IIT

Roorkee.

Waldo, S.(2007). On the use of student data in efficiency analysis-Technical efficiency in Swedish upper secondary school. Economics of Education Review ,26, 173 - 185. 